\title{
Mechanical properties of Cr-containing PM steels sintered in industrial conditions
}

\author{
Desislava Yordanova Mincheva ${ }^{1}$, Plamen Nedkov Petrov ${ }^{1}$ \\ 1 - Technical University of Varna, Department of Materials Science and Technology, 9010, 1 Studentska Street, Varna, Bulgaria \\ Corresponding author contact: mincheva_deabv.bg
}

\begin{abstract}
The objectives of this present research work are Cr-containing PM steels sintered in industrial conditions. The sintering was carried out in industrial furnace with $85 \% \mathrm{~N}_{2}+15 \% \mathrm{H}_{2}$ atmosphere at temperature of $\mathrm{T}=1140^{\circ} \mathrm{C}$, during $40 \mathrm{~min}$. Information about the mechanical properties of the investigated alloys is obtained, which contributes to further studies, connected with the application of chemical heat treatments such as oxidation and gas carbonitriding.
\end{abstract}

Keywords: Cr-containing, PM parts, copper alloying, industrial conditions, mechanical properties

\section{$1 \quad$ Introduction}

The properties of the PM sintered parts depend on the type of iron powder and sintering conditions. Generally PM requires a higher concentration of alloying elements than wrought counterparts in order to achieve similar characteristics. Driven by economic and environmental issues "Pometon Powder" designed new sinter-hardening PM steels with a minimum of alloying elements. Pometon SpA of Maerne, Italy, reported on the development of two new lean Cr-containing alloy powders designated ECOSINT A (Fe-1.4Cr-0.8Mo-0.4Ni-0.3graphite) and ECOSINT C (Fe-1.4Cr-0.8Mo-1.0Ni-0-1.9Cu0.3 graphite). Sintering of such Cr-containing PM steels is usually recommended to be carried out in nitrogen/hydrogen gaseous atmospheres in order to guarantee reduction of oxides and prevent further oxidation during processing. (Castro, F.2007), (Saccarola 2009), (Castro, F.2009).

Through these work the authors aim is to examine some mechanical properties of low Cr-containing PM steels after sintering in industrial conditions, such as initial information before further chemical heat treatments like oxidation, gas carbonitriding and oxicarbonitriding.

\section{Experimental procedure}

Investigations have been carried out on the following kinds of commercial iron powders and mixtures:

- EcosintC - complex alloy powder;

- EcosintHighCrA - complex alloy powder;

- Mechanical mixture made from EcosintHighCrA iron powder as a based powder and electrolytic copper powder in concentration of $99 \mathrm{wt} \% \mathrm{Fe}+1 \mathrm{wt} \% \mathrm{Cu}$.

The commercial grades of iron powders are manufactured by Pometon Powder Company - Italy.

The chemical composition of the powders is shown in Tabl.1. 
Table 1. Chemical composition of ferrous powders

\begin{tabular}{|l|c|c|c|c|c|c|}
\hline \multirow{2}{*}{ Powder/mechanical mixture } & \multicolumn{6}{|c|}{ Chemical composition, \% } \\
\cline { 2 - 7 } & $\mathbf{C r}$ & $\mathbf{M o}$ & $\mathbf{M n}$ & $\mathbf{N i}$ & $\mathbf{C u}$ & $\mathbf{C}$ \\
\hline ECOSINT C & 1,4 & 0,8 & 0,2 & 1,0 & 1,0 & 0,6 \\
\hline ECOSINTHighCrA & 2 & 0,8 & 0,2 & 0,4 & - & 0,7 \\
\hline $\begin{array}{l}\text { Mechanical mixture } \\
\text { (Fe+1wt\% Cu) }\end{array}$ & \multicolumn{7}{|c|}{ 99wt\%EcosintHighCr+1wt\%Cu. } \\
\hline
\end{tabular}

A set of samples were die pressed at 600MPa. The dimensions of the compacts are different for the different types of tests (Tabl. 2).

Table 2. Presssing die dimension of the experimental specimens

\begin{tabular}{|l|l|}
\hline Mechanical test & Shape/Size of samples \\
\hline $\begin{array}{l}\text { Impact toughness } \\
\text { Hardness (HRB) }\end{array}$ & Rectangular/10x10x50mm \\
\hline TRS & Rectangular/5x10x50mm \\
\hline
\end{tabular}

The pressed components were sintered in a channel furnace - pushing type in the $85 \% \mathrm{~N}_{2}: 15 \% \mathrm{H}_{2}$ atmosphere, at a temperature of $\mathrm{T}=1140^{\circ} \mathrm{C}$, during $40 \mathrm{~min}$.

To determine the impact strength (KC) of the specimens a Sharpy hammer was used. The samples used are rectangular cross-section $(10 \times 10 \mathrm{~mm})$ without notch.

To determine TRS rectangular specimens $(5 \times 10 \times 50 \mathrm{~mm})$ were used. The specimens are placed on supports with a fixed distance of $40 \mathrm{~mm}$ between them. The maximum force at which the sample is fractired is recorded. The transverse rupture strength was calculated using the formula (1):

$$
T R S=\frac{3 . F \cdot l}{2 . t^{2} b}, M P a
$$

$F$ - Maximum force, $\mathrm{N}$

$l$ - distance between supports, $\mathrm{mm}$

$t$ - sample thickness, mm

$b$ - sample width, mm

Tensile specimens were constructed and machined according to the drawing presented on Fig.1.

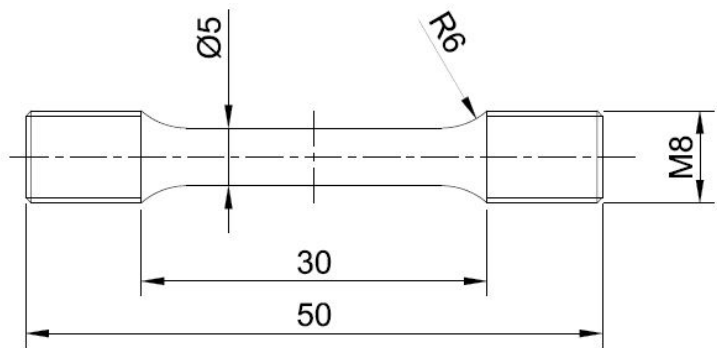

Fig. 1. Drawing of samples for tensile testing

For each test, 3 /three/ samples of each material were selected. 


\section{Results and discussion}

After sintering the registered density, determined after geometry method for the samples made from EcosintC and EcosintHighCrA is $6.7-7.0 \mathrm{~g} / \mathrm{cm}^{3}$. Samples made from the mechanical mixture with $1 \%$ $\mathrm{Cu}$ addition have a slightly higher density of 6.95 to $7.03 \mathrm{~g} / \mathrm{cm}^{3}$. This is most likely due to the addition of $1 \% \mathrm{Cu}$ to the basic iron powder, which further increases the density, as a result of the liquid phase sintering of $\mathrm{Fe}-\mathrm{Cu}$ system alloys and possibly to the higher specific density of the copper. The liquid copper fills the open pores and helps to increase not only the density but also the other properties.

In table 3 are shown the surface hardness indexes determined after Rockwell method, scale B (HRB).

Table 3. Surface hardness after sintering

\begin{tabular}{|c|c|c|}
\hline \multirow{2}{*}{ Material } & \multicolumn{2}{|c|}{ HRB } \\
\cline { 2 - 3 } & $\min$ & $\max$ \\
\hline ECOSINT C & 80 & 92 \\
\hline ECOSINTHighCrA & 85 & 94 \\
\hline $\begin{array}{c}\text { Mechanical mixture } \\
\text { (Fe+1wt\% Cu) }\end{array}$ & 95 & 97 \\
\hline
\end{tabular}

Samples made from the alloy iron ECOSINT C and ECOSINTHighCrA powders have approximately the same hardnesses. The slightly higher hardness of ECOSINTHighCrA is due to the alloying of iron with more chromium. The samples made from mechanical mixture with $\mathrm{Cu}$ addition have higher hardness (95-97HRB) than the samples made from pure powders. The high hardness corresponds to the high density of the samples made from the mechanical mixture. The resulting surface hardness is too low for these alloys compared to the literature data.

As expected, the impact strength of the samples was very low (fig. 2).This is due to the very nature of the investigated alloys. However, increased toughness (approximately $18 \mathrm{~J} / \mathrm{cm}^{3}$ ) is observed in samples made of mechanical mixture $(99 \% \mathrm{Fe}+1 \% \mathrm{Cu})$. Relatively low values for impact resistance, relative to reference data (Bueno, 2014) probably due to the unsuccessful martensite structure due to the insufficient cooling rate after sintering.

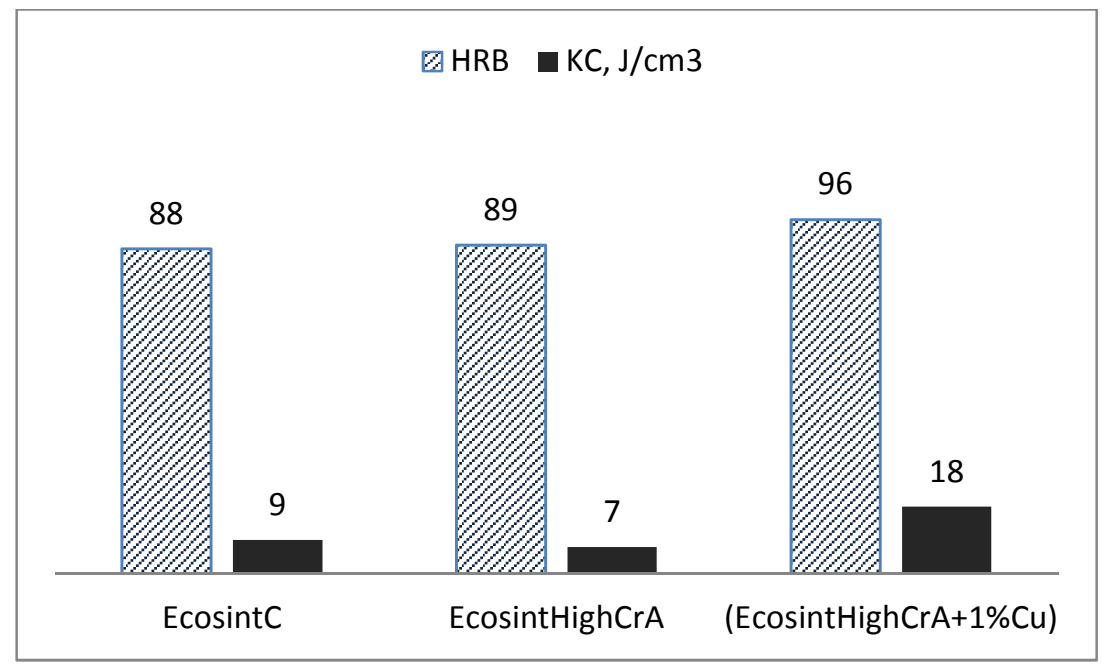

Fig. 2. Average result from surface hardness (HRB) and impact toughness (KC)

Based on the indicator diagrams from the machine, stress-strain diagrams (R-e) (fig 3, fig. 4, fig. 5), are constructed. The tensile diagrams correspond of diagrams of brittle materials, such as the sintered materials being studied.

The average results from tensile test and bending test are shown on Fig. 6. The tensile strength is approximately the same for all types of sintered materials. Samples made from a mechanical mixture 
have a slightly higher tensile strength $\mathrm{Rm}=815-855 \mathrm{MPa}$. The tensile strength of samples made from complex alloyed powder EcosintC is approximately 701MPa. Obviously, the introduction of copper powder into the base iron powders increases the tensile strength of the investigated alloys. Specimens made from iron powder EcosintHighCrA have lower bending strength and low tensile strength.

The tensile strength of the alloys being tested is approximately $30 \%$ lower than that reported in the alloy information brochures, but significantly outweigh other chromium containing alloys such as AstaloyCrL, AstaloyCrM and others. (Димитров, Д. 2008), (Salak A., 1997), (Cias A. 2016).

All tensile test charts are without a significant yield limit. In order to determine their apparent yield limits, it is necessary to carry out the tensile test using an extensometer.
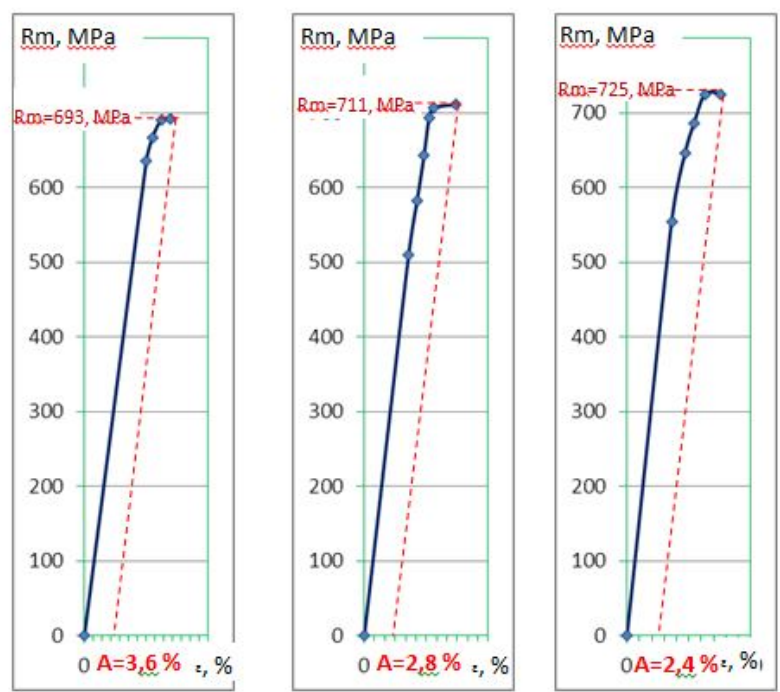

Fig. 3. Stress-strain diagrams of samples made from EcosintC powder
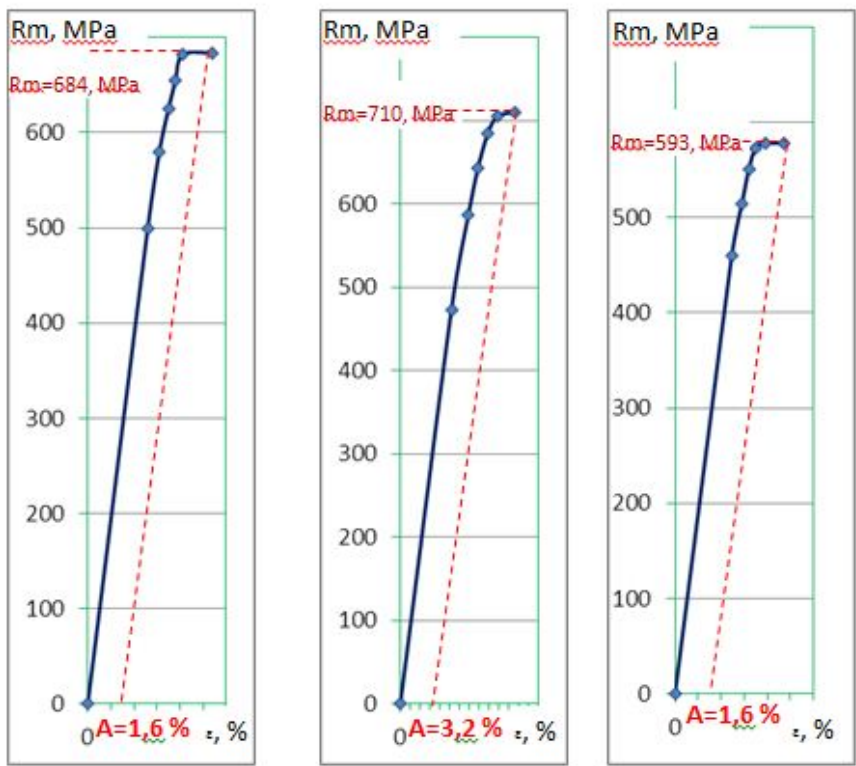

Fig. 4. Stress-strain diagrams of samples made from EcosintHighCrA powder 

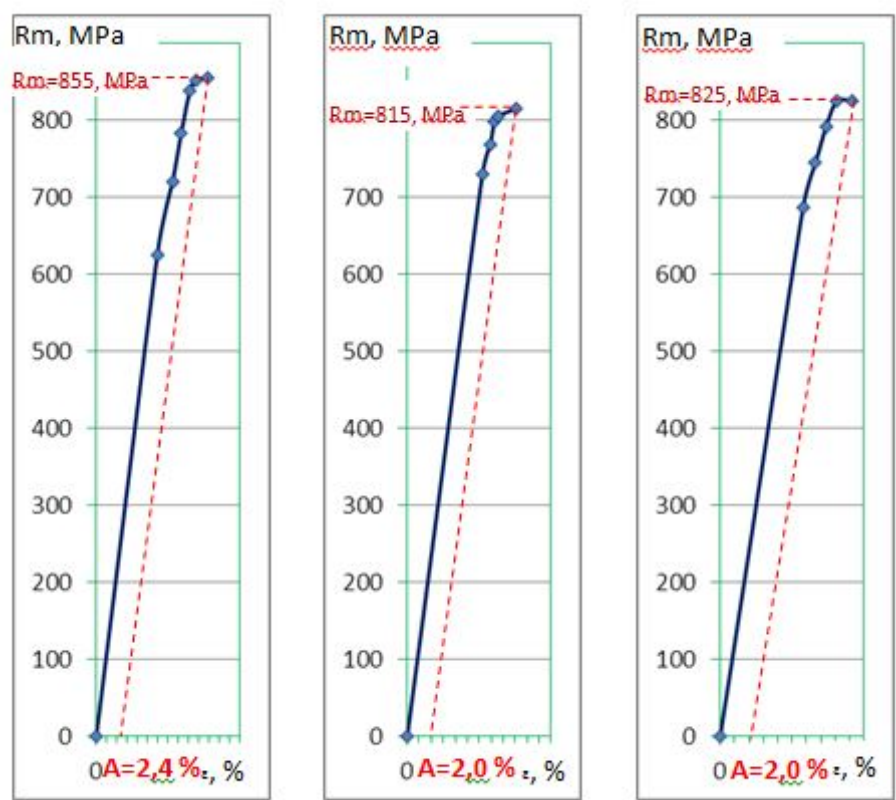

Fig. 5. Stress-strain diagrams of samples made from mechanical mixture

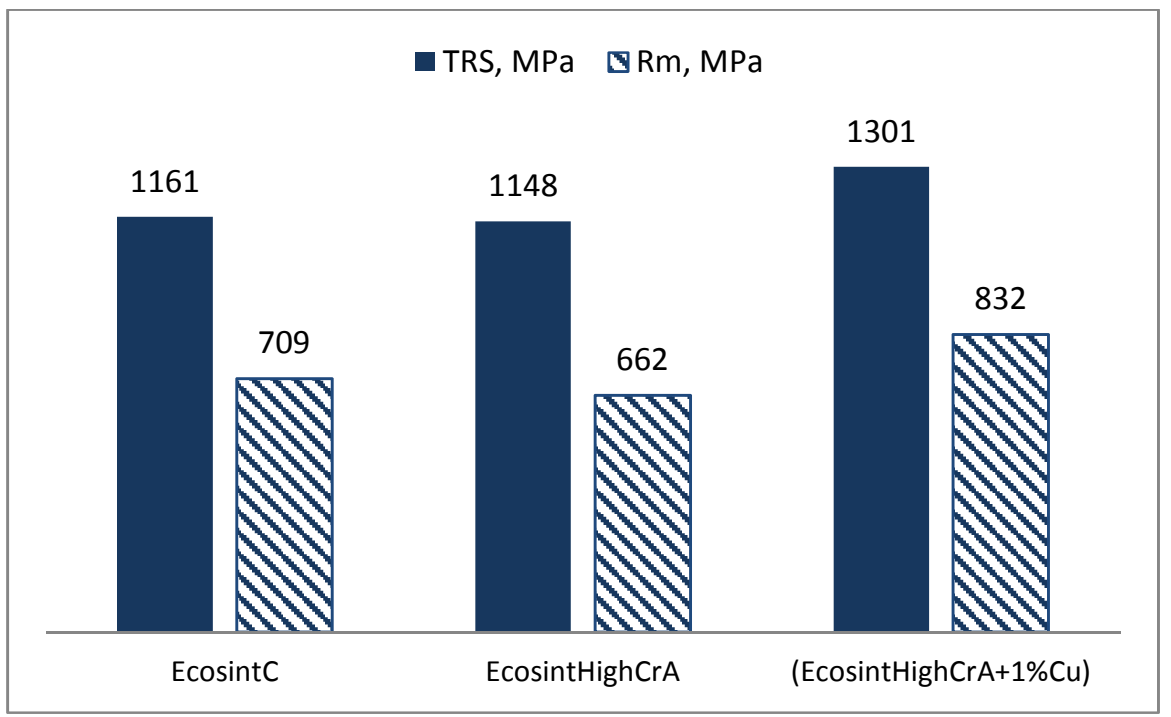

Fig. 6. Average results from TRS and tensile test

The bending strength (TRS) of the test pieces of the three types of alloys is approximately the same in the range 1160-1300MPa. The alloy with addition of 1\% copper surpasses the remaining alloys EcosintC and EcosintHighCrA and the values obtained are higher than those reported for the same alloys in a literary source (Donaldson, 2013), sintered under similar conditions. 


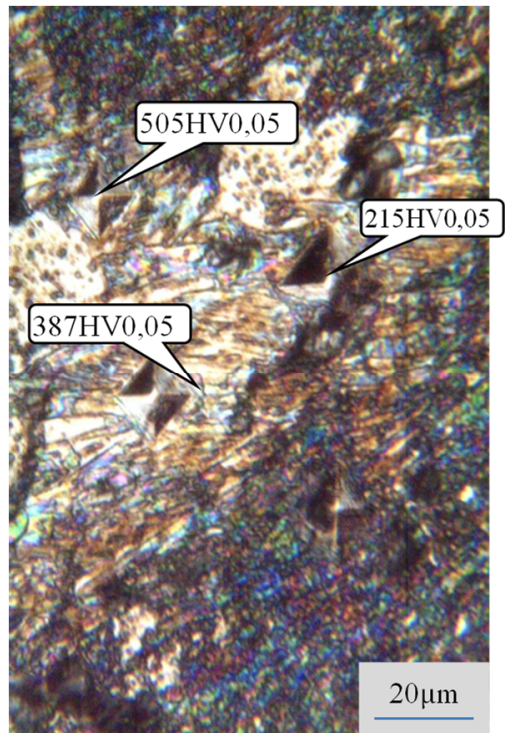

a)

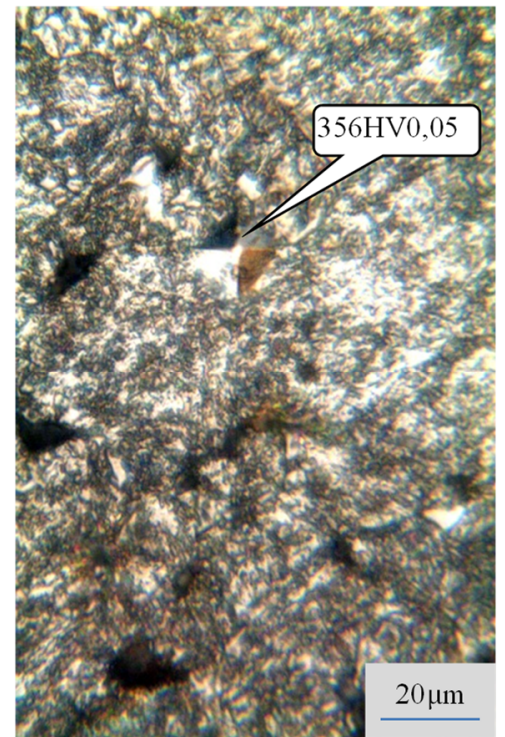

b)

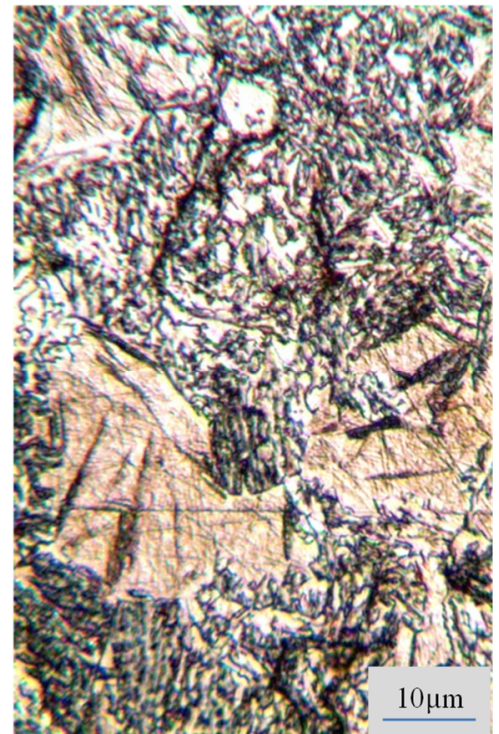

c)

Fig. 7. Microstructure of sintered alloys - a)EcosintC; b)EcosintHighCrA;

The figures $7 \mathrm{a}$ and $7 \mathrm{~b}$ shows the microstructures of sintered alloys made of EcosintC $(1,4 \mathrm{Cr}-1 \% \mathrm{Cu}$ $1 \% \mathrm{Ni}-0,6 \% \mathrm{C})$ and EcosintHighCrA $(2 \% \mathrm{Cr})$. The metallographic study showed the formation of a non-homogeneous structure, predominantly a fine pearlite (sorbite) with microhardness of 215300HV0.05. Martensite-bainite zones are observed, as a white areas with microhardnesses 387$550 \mathrm{HV} 0.05$.

The figure 7c shows the microstructure of the sintered mixture that is considerably more non-homogeneous after its phase compositions compare to the structures of samples made from EcosintC and EcosintHighCrA. The metallographic analysis shows that its fundamental part represents a fine pearlite (sorbite) at the microhardness of 325HV0.05.Martensite-beanite zones are observed with high microhardness 820HV0.05.

The obtained structures once again prove that the achieved cooling rate after sintering in the abovementioned conditions is insufficient to obtain a martensitic structure.

\section{Conclusion}

The obtained structures once again prove that the achieved cooling rate after sintering in the industrial conditions is insufficient to obtain a martensitic structure.

The mechanical properties of the alloys obtained under the given conditions of caking are lower than those given in the reference data but exceed most of the other alloys traditionally sintered in Gama Sinter and can be recommended in making more responsible details.

In view of the results obtained, an additional improvement of the properties of the alloys after sintering can be sought with subsequent chemical heat treatment.

\section{References}

Castro, F., Sainz, S., Lindsley, B., and James, W. B. (2007). The Effect Of Sintering Conditions And Composition On The Mechanical Response Of Cr Containing PM Steels. Proc. EuroPM2007, vol.1, Sintered Steels, Tolouse, France.

Saccarola, S., Sainz, S., Karuppannagounder, A., Castro, F.(2009). Hardenability and mechanical properties of novel sinter-hardening PM steels. Proc. PowderMet, vol. 10, 52-61, Las Vegas, USA, 2009. 
Castro, F., Karuppannagounder, A., Sainz, S., Saccarola, S., Bellin, G., Bueno, S. (2009). Influence of selected elements on the hardenability and mechanical properties of recently developed sinterhardening PM steels. Procs. EuroPM2009, Sintered Steels II, Copenhagen, Denmark, 2009.

Bueno, S., Saccarola, S., Sainz, S. (2014). Sinter-hardening response from a Cr-containing iron based powder during industrial sintering. $7^{\text {th }}$ International Powder Metallurgy Conference \&Exhibition, June 24-28, 2014, Ankara, Turkey

Димитров, Д. (2008). Димитров, ДМ, ПН Златева, СД Харизанова. Влияние на спечената структура на железните сплави върху механичните им свойства, Механика на машините, Година XVI. Книга, 5, 77.

Salak A., (1997). Ferrous Powder Metallurgy, Cambridge International Science Publishing p.378

Cias A. (2016). Mechanical properties of hybrid Cr, Mn, and Si-containing PM steel when sintered in a local micro-atmosphere, Kovove Mater. 542016 269-278, DOI: 10.4149/km 20164269

Donaldson I.,(2013) PM Steels containing Cr and Mn for High Performance PM Applications, Advances in Powder Metallurgy \& Particulate Materials, June 24 - 27, 2013 Chicago, IL

\section{Internet sources}

http://www.pometon.com 